\title{
The Effect of Spiritual Care Education on Hospice Nurses' Competence in the Assessment and Implementation of Spiritual Care with their Patients: A Quasi-experimental Study
}

Vida Anita Amoah

Cedarville University, amoahv@gmail.com

Follow this and additional works at: http://digitalcommons.cedarville.edu/nursing theses

Part of the Nursing Commons

\section{Recommended Citation}

Amoah, Vida Anita, "The Effect of Spiritual Care Education on Hospice Nurses' Competence in the Assessment and Implementation of Spiritual Care with their Patients: A Quasi-experimental Study" (2015). Master of Science in Nursing Theses. 18.

http://digitalcommons.cedarville.edu/nursing_theses/18 

THE EFFECT OF SPIRITUAL CARE EDUCATION ON HOSPICE NURSES'

COMPETENCE IN THE ASSESSMENT AND IMPLEMENTATION OF SPIRITUAL CARE WITH THEIR PATIENTS: A QUASI-EXPERIMENTAL STUDY

A thesis submitted in partial fulfillment of the requirements for

the degree of Master of Science in Nursing

By

Vida Anita Amoah

B.S.N. Northern Kentucky University, 2009

2014

Cedarville University 


\begin{abstract}
Background: There is a well-documented relationship between spiritual care and improved quality of life for hospice and palliative care patients. However, nurses report that they receive little education on how to provide spiritual care. This lack of education results in nurses' reluctance to provide spiritual care for their patients.
\end{abstract}

Theoretical Model: The Faith-Hope-Love Model of Spiritual Wellness (FHLMSW) provides a theoretical understanding of the human spirit, spirituality, spiritual wellness, and spiritual needs.

Purpose: The purpose of this study was to use the FHLMSW to examine the effects of spiritual care education on Hospice Nurses' competence on how to assess and implement spiritual care with their patients.

Method: The study employed a pretest posttest quasi- experimental no control group design, with a convenience sample of 49 hospice nurses. Participants completed the Spiritual Care Competency Scale (SCCS) before and after a 45 minute spiritual care education in-service. Paired t-tests were used to determine differences between pretest and posttest scores.

Results: Paired t-test revealed statistical significant on two of the six core domains of the SCCS which were; professionalism and improved quality of care $(\mathrm{p}=0.000)$ and personal support and patient counseling $(\mathrm{p}=0.01)$. There was also a significant change in two knowledge questions developed by the researcher $(\mathrm{p}=.00)$. There was a trend toward a significant improvement in referral $(\mathrm{p}=0.06)$ and assessment and implementation $(\mathrm{p}=0.15)$ scores.

Relevance to Nurses: A proper understanding of spiritual care and its importance could assist the Hospice nurse in detecting the unmet spiritual needs of patients to facilitate good quality of 
life and achieve a peaceful and dignified death.

Conclusion: The findings of this study provide preliminary evidence that spiritual care education using the FHLMSW can give effective direction to nurses on providing spiritual care as well as increase their confidence in providing spiritual care. 


\section{Acknowledgements}

I would like to express my deepest appreciation to Dr. Sharon Christman, director of research studies who was the most instrumental in directing me to develop a project of this magnitude; Joy Higginbotham faculty member and my academic advisor for her tremendous support and advice. I also would like to extend my special thanks to the senior leadership of Hospice of Dayton for been extremely helpful and opening their doors for this project to be conducted in their facility. I also want to extend my appreciation to my husband Eric Boafo for all his love, support and encouragement throughout this project. 


\section{Table of Contents}

Abstract

iii-iv

Acknowledgements

V

Table of Contents

vi-vii

Chapter 1

$1-4$

Introduction and Literature Review

$1-2$

Barriers

2-3

Education

3-4

Chapter 2

$5-8$

Theoretical Model

5-8

Purpose

8

Hypothesis

8

Chapter 3

9-12

Participants

9

Design

Measuring tools

10-11 
List of Figures

Figure 1

List of Tables

Table 1

Table 2

10-11

Table 3

13-15 
Table 4

15-16

Table 5

18 


\section{Chapter 1}

\section{Introduction and Literature Review}

Most cancer patients consider attention to spiritual concerns as an important part of their care by physicians (87\%) and nurses (85\%) (Vallurupalli, Lauderdale, Balboni Phelps, Block, \& Balboni, 2012) and expect healthcare professionals to provide spiritual care for them (Balboni, Vanderwerker, Block Paulk, Christopher, Peteet, \& Prigerson, 2007). Researchers have reported that people who are diagnosed with any form of life limiting or terminal disease value the importance of spiritual care and spiritual well being. Patients who are diagnosed with cancer reported that religion and spirituality are some of the most important resources used to cope with the disease and its treatment (Vallurupalli et al., 2012). A study by Balboni et al., (2007) reported that $88 \%$ of the study population who were cancer patients claimed religion to be important to them. Nevertheless $72 \%$ of these same patients claimed that their spiritual needs were minimally met or not met at all by medical professionals.

In $2012,91 \%$ of advanced cancer patients reported that they had a spiritual need; and that those who received less spiritual care than they desired experienced increased depressive symptoms ( $\mathrm{p}=0.0013)$, and reduced sense of spiritual meaning and peace $(\mathrm{p}=042$; Pearce, Coan, Herndon, Koenig, \& Abernethy). These results are similar to those found with breast cancer patients who reported increased spiritual wellbeing was associated with decreased levels of stress $(\mathrm{p}<0.001, \mathrm{r}=-0.44)$, anxiety $(\mathrm{p}<0.001, \mathrm{r}=-0.27)$ and depression $(\mathrm{p}<0.001, \mathrm{r}=-0.48$; Musarezaie, Naji, Esfahani, et al., 2012).

In 2013, Philips and Lazenby reported that when the spiritual needs of patients were not fully met, overall quality of life decreased. In 2012, $84 \%$ of advanced cancer patients reported 
that religion and spirituality were coping mechanisms and were associated with better quality of their life (Vallurupalli et al.). Furthermore, spiritual support by medical professionals has made significant association with a patient's quality of life ( $\mathrm{p}=0.0003$ ) (Balboni et al., 2007). In 2014, Martínez, \& Custódio examined the relationship between mental health and spiritual wellbeing and found that decreased spiritual wellbeing was associated with poor mental health, presence of psychological stress, sleep disturbances, and psychosomatic complaints. Furthermore, spiritual care has a positive outcome for patients going through any form of pain or suffering (Kale, 2011).

\section{Barriers to Spiritual Care}

Nurses play a key role in hospice and palliative care, as they advocate for patients and families and provide direct care on a continuous basis (Krisman-Scott \& McCorkle, 2002). The multidisciplinary palliative care approach means that hospice and palliative care nurses require a consistent theoretical foundation in order to be confident, able to explain, and carry out their role. (Dobrina, Tenze \& Palese, 2014). Unfortunately, there are several challenges that nurses encounter when it comes to providing spiritual care. In 2011, nurses reported that it was challenging to find the appropriate language to assess spiritual needs; and although they were aware there were spiritual care tools available, they were not sure what these tools were (Abbas \& Dein). In the same study, nurses and doctors reported that most of the training they received focused on the physical and psychological needs of their patients rather than their spiritual needs. In 2009, Bailey, Moran, and Graham revealed that nurses acknowledged spending time with patients as a very essential intervention when it comes to spiritual care. However, finding time to be present with the patient was one of the greatest challenges for the nurses due to their busy 
schedules and heavy work load.

\section{Spiritual Care Education}

According to Mitchell, Bennett, and Manfrin-Ledet (2006), spiritual competence is the basic foundation for nurses to enhance hope, peace and meaning for their patients. However, multiple studies have revealed how nurses feel less competent in addressing spiritual care issues (Pike, 2011). In an attempt to bridge that incompetency, Meyer (2003) emphasized the need for nursing programs to expand education on spirituality which will help students gain more awareness of their own spirituality and allow them to administer quality spiritual care to patients.

In 2008, Van Leeuwen, Tiesinga, Middel, Post, and Jochemsen conducted a longitudinal study on the effectiveness of a 6 and 20 -week spiritual care education program on spiritual care competence using the SCCS. These researchers found a significant increase in competence for spiritual care among the intervention group after they received six week education; assessment and implementation of spiritual care $(\mathrm{p}=0.001)$, professionalization and improving quality of spiritual care $(p=0.021)$, personal support and counseling of patients $(p=0.031)$. The researchers

found apparent significant effects in the 20 weeks intervention on all the six domains; assessment and implementation of spiritual care $(\mathrm{p}=0.00)$, professionalization and improving quality of spiritual care $(\mathrm{p}=0.00)$, personal support and patient counseling $(\mathrm{p}=0.00)$, referral to professionals $(\mathrm{p}=0.00)$, attitude towards patient's spirituality $(\mathrm{p}=0.00)$, and communication (0.033). However, in 2014 Linegang found similar results after just a 45-minute spiritual care intervention using the Faith, Hope, and Love Model of Spiritual Wellness. In this study, there was a significant increase in the nurses' perceived competence after the 45-minute intervention, with significant changes in four of the six domains of the SCCS: communication $(p=0.01)$, 
assessment and implementation of spiritual care $(\mathrm{p}=0.00)$, personal support and patient counseling $(\mathrm{p}=0.00)$, and professionalization and improving quality $(\mathrm{p}=0.00)$. 


\section{Chapter 2}

\section{Conceptual Framework}

This study was guided by the Faith-Hope-Love Model of Spiritual Wellness (FHLMSW) developed by Christman \& Mueller (2015). The model was developed for the purpose of describing the human spirit, defining spirituality, and provide a better understanding of what it means to be spiritually well versus spiritually unwell (See Figure 1). The first part of the model (\#1) describes the person as both spirit and body. While these two parts are different, they are functionally unified with interdependence and causal connection.

The second part of the model (\#2) defines spirituality. The FHLMSW defined of spirituality based on a study of the philosophical, theological, and nursing literature and is: "the relationship of our embodied selves to God, others, the environment, and self which results in a search for meaning and purpose". 
$\underline{\text { Figure } 1}$

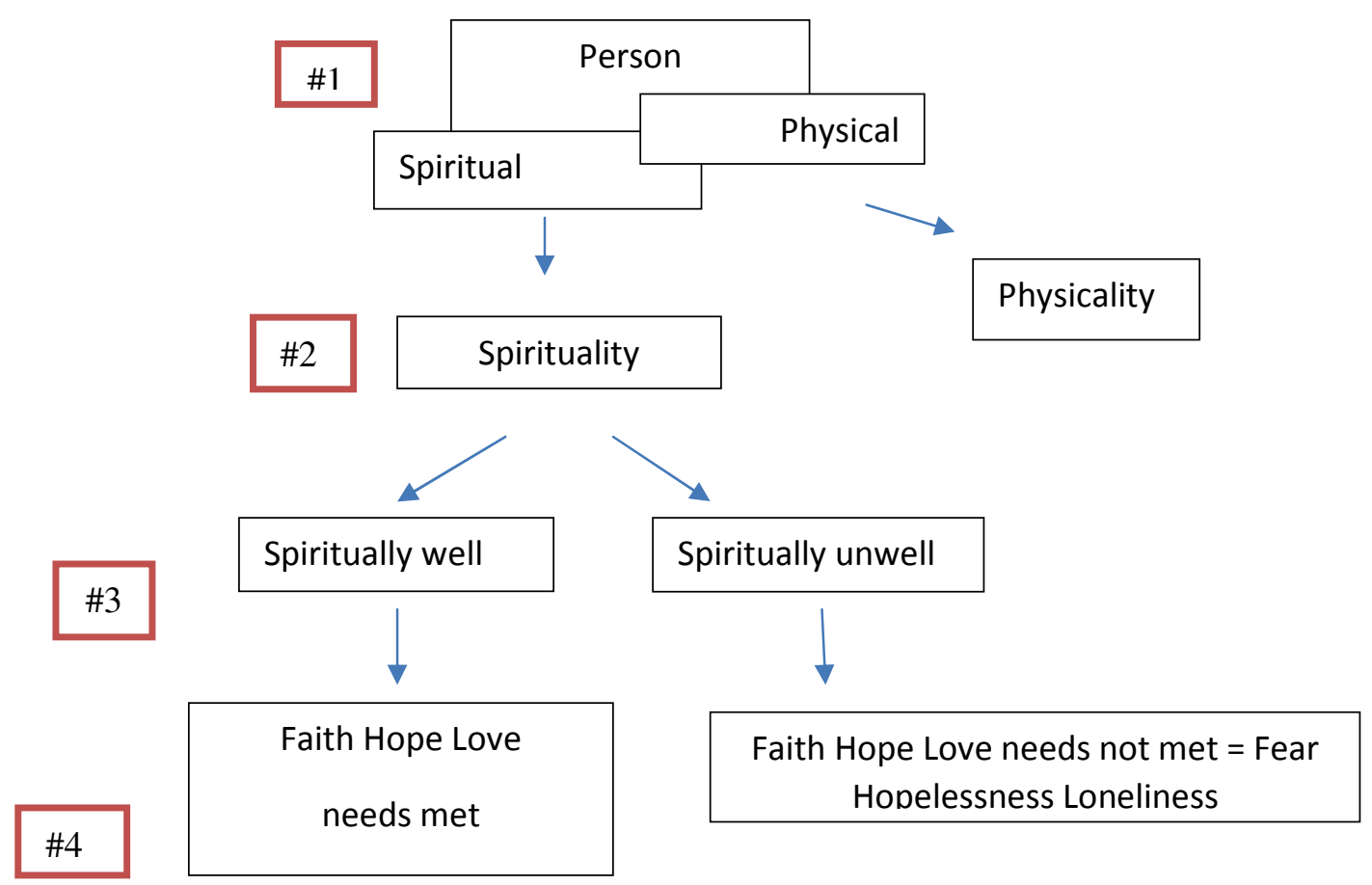

The third part of the model (\#3) is where the concept of spiritual wellness is further defined. Christman \& Muller (2015) identified the two ends of the spirituality spectrum as spiritually well and spiritually unwell. Spiritually well was conceptually defined as "a person having their faith, hope, and love needs met"; while spiritually unwell was defined as "a person not having their faith, hope, and love needs met resulting in fear, hopelessness, and loneliness". Finally, in the fourth part of the model (\#4), Christman identifies the three essential spiritual needs as faith, hope, and love, and provides conceptual definitions for each (Table 1). 
Table 1 Definitions of Faith, Hope, and Love

SPIRITUAL NEED

DEFINITION

\begin{tabular}{l|l}
\hline FAITH & $\begin{array}{l}\text { Belief or trust in someone or something. For the Christian this need is } \\
\text { primarily met through faith in Jesus Christ; however all people need to } \\
\text { hove faith in something whether temporal or eternal. When this need is } \\
\text { not met, fear is the result. } \\
\text { Hope is a person's confidence that their faith has not been misplaced. } \\
\text { For the Christian, this need is met by their hope that Jesus is powerful } \\
\text { enough to keep His promise of life with Him in heaven; however all } \\
\text { people have a need to be confident that what they believe will come to } \\
\text { pass. When this need is not met, hopelessness is the result. } \\
\text { Love is every person's greatest spiritual need and for the Christian is } \\
\text { met by a love relationship with Jesus Christ. However, all people have } \\
\text { the need to receive love from others through expressions of: patience, } \\
\text { kindness, forgiveness, humbleness, protection from harm, truthfulness, } \\
\text { endurance, and selflessness. When the need for love is not met, } \\
\text { loneliness is the result. }\end{array}$
\end{tabular}

The FHLMSW proposes that when spiritual needs are not met, a person is spiritually unwell, and therefore struggles with finding meaning and purpose (Christman \& Muller, 2015). On the other 
hand, if spiritual needs are met, they can be considered spiritual well, and therefore have meaning and purpose (Christman \& Muller, 2015).

\section{Purpose}

The purpose of this study was to use the FHLMSW to examine the effects of spiritual nursing care education on Hospice Nurses' spiritual care competence.

\section{Hypothesis}

There will be significant increase in the hospice nurses' perceived competence following the education session on spiritual care guided by the FHLMSW. 


\section{Chapter 3}

\section{Methods}

\section{Participants}

This study was conducted with nurses who work at a large Hospice inpatient facility that serves over 7 counties in the Midwest area. Convenience sample of 49 nurses who work at the inpatient hospice participated in the study. Nurses were informed that participation was voluntary, confidential, and anonymous. Inclusion criteria were: nurses who work for the Hospice where the intervention occurred, and able to read and understand English. There were no exclusion criteria. One "tradition" credit (a type of continuing education credit required by the institution) was provided by the Hospice Education Department as incentive for completion of the survey. Completion of the pretest and posttest was not a requirement to receive the tradition credit.

\section{Design}

The study's design was a pretest posttest quasi-experimental with no control group. A convenience sampling technique was used to recruit the nurses, and the spiritual care education was during a required staff meeting. The unit manager sent out an email to all the nurses a week prior to the meeting with an agenda and included clearly that there was going to be an in-service presentation as part of a research study. The in-service was presented by a university faculty member who also developed the model used for the study. The Spiritual Care Competency Scale (SCCS) was administered pre and post intervention via turning point to measure their competency on spiritual care. Turning point is a software program that allows participants to answer questions as projected on a screen with the use of a remote. The in-service was presented at three different times to accommodate the nurses' schedules. 


\section{Measurement Tool}

The dependent variable of this study was Spiritual Care Competence. Spiritual Care Competence is operationally defined by Van Leeuwen (2004) as the score on the individual domains of the Spiritual Care Competency Scale (SCCS). The SCCS has 27 items on a 5-point Likert scale where 1 means completely disagree, 2 disagree, 3 neither agree or disagree, 4 agree, and 5 fully agree as used in a study by Tiesinga, Middel, Post, Jochemsen, \& Van Leeuwen, (2009). The SCCS consists of six core domains of spiritual care-related nursing competencies and the elements include 1) assessment and implementation of spiritual care, 2) professionalization and improving quality of spiritual care, 3) personal support and patient counseling, 4) referral to professionals, 5) attitude towards patient's spirituality and 6) communication (Tiesinga et al., 2009). The reliability and validity of the SCCS was tested by Tiesinga et al. (2009) and the scale was found to be both reliable and valid, with good internal consistency, sufficient average inter-item correlations and good test-retest reliability (See Table 2). The current researcher developed two knowledge questions which were added to the SCCS to determine the nurses' self assessment of their knowledge. These questions were: 1) I have sufficient knowledge to conduct spiritual assessment; 2) I have sufficient knowledge to deliver spiritual nursing care.

$\underline{\text { Table } 2}$

\begin{tabular}{|l|l|}
\hline SSCS Dimensions & Cronbach's alpha \\
\hline Assessment and implementation of spiritual care & 0.82 \\
\hline Professionalization and improving quality of spiritual care & 0.82 \\
\hline
\end{tabular}




\begin{tabular}{|l|l|}
\hline Personal support and patient counseling & 0.81 \\
\hline Referral to professionals & 0.79 \\
\hline Attitude towards patient's spirituality & 0.56 \\
\hline Communication & \\
\hline
\end{tabular}

\section{Location \& Intervention}

The 45-minute in-service was held at the facility's conference room where most meetings are held for the employees. The presentation was provided by a $\mathrm{PhD}$ prepared nurse who developed the FHLMSW (Christman and Mueller, 2015). At each in-service, a power point was used to present faculty information, and there were between 10-20 nurses which allowed for discussion and questions throughout.

\section{Data Analysis}

The results of the pre and posttest scores were compared and statistical differences analyzed, using the pair t-test on SPSS software. The researcher tested the research hypothesis with a $95 \%$ confidence interval and $\mathrm{p}$ value $<0.05$.

Demographic variables included age, race, level of education, religious affiliation, university attended, years of nursing experience, and frequency of providing spiritual care. The frequency in the percentages of the demographic variables was determined using the SPSS software.

\section{Ethical considerations}

The senior leadership of Hospice approved this study to be conducted at the facility; and 
approval from Cedarville IRB was obtained. At the beginning of the in-service, the researcher explained to the participants that participation is voluntary and that completing the SCCS via turning point was considered as consent to participate in the study. Participants were also informed that information collected was confidential and anonymous. The participants received 1 tradition credit for the completion of the educational session which was not dependent on them participating in the study. 


\section{Chapter 4}

\section{Results}

Demographic characteristics of the participants are presented in Table 3. The sample consisted of 49 hospice nurses. About half the participants in the study were under 40 years of age $(50 \%)$. The majority of the nurses were female (97.3\%), Caucasian (89.7\%), and Christian (91.7\%), while less than half of them went to a faith based university (35.9\%). About $32 \%$ of the participants had under ten years of nursing experience, while most of them provided spiritual care at least twice a month, and many provided spiritual care daily (32.5\%).

$\underline{\text { Table } 3}$ Demographics

\section{Variables Frequency Percentage}

$$
(n=49)
$$

\begin{tabular}{l|ll}
\hline Gender & 36 & \\
Female & 1 & $97.3 \%$ \\
Male & & $2.7 \%$ \\
Race & 35 & $89.7 \%$ \\
Caucasian & 2 & $5.1 \%$ \\
African American & 2 & $5.1 \%$ \\
Hispanic & & \\
Age & 13 & $32.5 \%$ \\
$20-30$ & 7 & $17.5 \%$ \\
$30-40$ & 5 & $30.0 \%$ \\
$40-50$ & 12 & \\
$50-60$ & & \\
\hline
\end{tabular}




\begin{tabular}{|c|c|c|}
\hline $60+$ & 3 & $7.5 \%$ \\
\hline \multicolumn{3}{|l|}{ Education } \\
\hline Associate's Degree & 23 & $59.0 \%$ \\
\hline Bachelor's & 11 & $28.2 \%$ \\
\hline Diploma & 3 & $7.7 \%$ \\
\hline Master's & 2 & $5.1 \%$ \\
\hline \multicolumn{3}{|l|}{ University Type } \\
\hline Secular & 25 & $64.1 \%$ \\
\hline Faith Based & 14 & $35.9 \%$ \\
\hline \multicolumn{3}{|l|}{ Religious Affiliation } \\
\hline Christian & 33 & $97.1 \%$ \\
\hline Other & 3 & $8.3 \%$ \\
\hline \multicolumn{3}{|c|}{ Practicing Member of Religion } \\
\hline Yes & 33 & $78.6 \%$ \\
\hline No & 9 & $21.4 \%$ \\
\hline \multicolumn{3}{|l|}{ Years of Experience } \\
\hline $1-5$ & 9 & $22.5 \%$ \\
\hline $6-10$ & 13 & $32.5 \%$ \\
\hline $11-15$ & 3 & $7.5 \%$ \\
\hline $16-20$ & 2 & $5.0 \%$ \\
\hline $20+$ & 13 & $32.5 \%$ \\
\hline \multicolumn{3}{|c|}{ Frequency of Spiritual Care } \\
\hline Not At All & 14 & $10.0 \%$ \\
\hline
\end{tabular}




\begin{tabular}{l|ll}
\hline Daily & 13 & $32.5 \%$ \\
$1-2 X$ week & 17 & $42.5 \%$ \\
$1-2 X$ month & 6 & $15.0 \%$ \\
\hline
\end{tabular}

We found that there was a significant improvement in two of the six spiritual care domains: professionalism and improving quality of spiritual care and personal support and patient counseling (Table 4). Furthermore, there was a significant improvement in self-reported knowledge and a trend toward improvement in referral to professionals and assessment and implementation. Because the pretest scores were so high, there was no change in attitude and communication.

Table 4. Differences between pretest and posttest scores paired t-test

\begin{tabular}{|c|c|c|c|}
\hline Subscale & Pre-test & Post -test & P-value \\
\hline Knowledge $* *$ & 6.4 & 7.9 & .000 \\
\hline $\begin{array}{l}\text { Assessment and implementation of spiritual care. } \\
\qquad \text { Range } 0-30\end{array}$ & 23.3 & 24.5 & .150 \\
\hline $\begin{array}{l}\text { Professionalism and improving the quality of } \\
\text { spiritual care ** } \\
\text { Range } 0-30\end{array}$ & 18.9 & 21.5 & .000 \\
\hline $\begin{array}{l}\text { Personal support and patient counseling** Range } 0 \text { - } \\
30\end{array}$ & 23.2 & 24.7 & .01 \\
\hline Referral to professionals & 11.9 & 12.9 & .06 \\
\hline
\end{tabular}




\begin{tabular}{ll|l|l|l}
\hline 15 & & & & \\
\hline Attitude towards patient spirituality & Range 0- & 17.7 & 17.7 & N/A \\
20 & Range 0-10 & 9.1 & 9.1 & N/A \\
\hline Communication & & & & \\
\hline$* *$ significant change.
\end{tabular}




\section{Chapter 5}

\section{Discussion}

Two of the barriers to nurses providing spiritual care are education and competence. The results of this study show that a 45-minute nursing education in-service can overcome both of these barriers with a group of Hospice nurses. The findings of this study are consistent with the work done in 2014 by Linegang, however we did have some differences in our findings as compared to hers.

Based on the results of Linegang (2014), we expected to find a significant increase in scores on four domains of the SCCS and on knowledge. These four domains were 1) professionalism and improved quality of care, 2) personal support and patient counseling, 3) assessment and implementation of spiritual care, and 4) communication. We did not expect to find any change in 5) referral to professionals, and 6) attitude towards patient spirituality because the in-service did not focus on referrals, and we expected hospice nurses to already have a good attitude toward spiritual care. While we did find significant change in knowledge, and two of the four domains as expected, we did not see a significant increase in either: assessment and implementation of spiritual care, or communication. As a result, we decided to compare our pretest scores with the pretest scores of Linegang (2014) (see Table 3). 
Table 5 Comparison of current study baseline scores with Linegang

\begin{tabular}{|l|l|l|}
\hline Subscale & Current study & Linegang \\
\hline Assessment and implementation of spiritual care** & 23.3 & 21.2 \\
\hline $\begin{array}{l}\text { Professionalism and improving quality of spiritual care**** } \\
(0-30)\end{array}$ & 18.9 & 19.8 \\
\hline $\begin{array}{l}\text { Personal support and patient counseling**** } \\
(0-30)\end{array}$ & 23.2 & 21.7 \\
\hline $\begin{array}{l}\text { Referral to professionals } \\
(0-15)\end{array}$ & 11.9 & 12 \\
\hline $\begin{array}{l}\text { Attitude towards patient spirituality } \\
(0-20)\end{array}$ & 17.7 & 17.2 \\
\hline $\begin{array}{l}\text { Communication** } \\
(0-10)\end{array}$ & 9.7 & \\
\hline
\end{tabular}

**Significant change Linegang (2014)

**Significant change current study

When we compared our pretest scores to that of Linegang, we found that in both Assessment and implementation and communication, Hospice nurses' had about 2 point higher pretest scores than the pediatric nurses'. We believe that this could account for the reason we did not find significant improvement in these domains.

\section{Strengths and limitations}

There is a well-documented view that spiritual care is important to patients, and yet only a few studies have reported the results of spiritual care education with nurses. This study is the 
only one to date to report the success of a 45-minute spiritual care education intervention with Hospice nurses' spiritual care competency. After the education, some of the nurses verbally reported that even though they provide spiritual care on a daily basis, the in-service enlightened them on key points of spiritual care, provided effective direction on providing spiritual care, and increased their confidence in providing spiritual care. They also stated that they felt this would benefit their patients and families. Some nurses also reported that the in-service education has personally shaped their perception on interacting with others because they learned that through interaction with one another, a person's spirit can be either encouraged or broken.

On the other hand, this study also had some limitations. The sample size was small and it was a convenience sample from a specific population, therefore our findings may not be generalized to other populations. Another limitation to this study was that the people who were late missed the demographics and some pre-test questions which probably affected the results. Another limitation was that the in-service was conducted during a staff meeting therefore participants included some night shift nurses who had worked that night prior to the in-service in the morning and seemed very exhausted. This could have an impact on how the nurses answered the questions.

It is of note that over $90 \%$ of the Hospice nurses in this study self-identified as Christian. While the FHLMSW was developed for Christian nurses (Christman \& Mueller, 2015), the authors do state that it could be effective in helping nurses of all faiths who provides spiritual care. However, how the high number of Christian nurses in this study affected the outcome is not known. 


\section{Conclusion}

The findings of this study support the use of the FHLMSW as a foundation for teaching spiritual care to nurses in a Hospice setting. Furthermore, it is significant that even a short (45minute) intervention can increase a nurses' self-reported competence in providing spiritual care. Considering that education is a barrier to nurses' providing spiritual care, health care organizations should consider implementing even short continuing education courses to help their nurses provide the spiritual care that their patients desire, and that accrediting bodies require. These findings from this study may help expand our understanding on how spiritual care education can promote spiritual care among American nurses. 


\section{References}

Abbas, S. Q., \& Dein, S. S. (2011). The difficulties assessing spiritual distress in palliative care patients: A qualitative study. Mental Health, Religion \& Culture,14(4), 341-352. doi:10.1080/13674671003716780

Bailey, M., Moran, S., \& Graham, M. (2009). Creating a spiritual tapestry: Nurses' experiences of delivering spiritual care to patients in an Irish hospice. International Journal of Palliative Nursing, 15(1), 42-48.

Balboni, T. A., Vanderwerker, L. C., Block, S. D., Paulk, M. E., Christopher, S., Peteet, J. R., \& Prigerson, H. G. (2007). Religiousness and spiritual support among advanced cancer patients and associations with end of life treatment preferences and quality of life. Journal of Clinical Oncology, 25(5), 555-560.

Christman, S., \& Mueller, J. (2015). Faith-Hope-Love Model of Spiritual Wellness: A theoretical model of spirituality from a Christian worldview. Unpublished typescript.

Dobrina, R., Tenze, M., \& Palese, A. (2014). An overview of hospice and palliative care nursing models and theories. International Journal of Palliative Nursing, 20(2), 75-81.

Galek, K. K., Flannelly, K. J., Vane, A. A., \& Galek, R. M. (2005). Assessing a patient's spiritual needs: A comprehensive instrument. Holistic Nursing Practice, 19(2), 62-69.

Hsiao, S., Gau, M., Ingleton, C., Ryan, T., \& Shih, F. (2011). An exploration of spiritual needs of Taiwanese patients with advanced cancer during the therapeutic processes. Journal of Clinical Nursing, 20(7-8), 950-959. doi:10.1111/j.1365-2702.2010.03278.x 
Kale, S. S. (2011). Perspectives on spiritual care at hospice Africa Uganda. International Journal of Palliative Nursing, 17(4), 177-182.

Krisman-Scott, M. A., \& McCorkle, R. R. (2002). The tapestry of hospice. Holistic Nursing Practice, 16(2), 32-39

Linegang, B., (2014). A quasi-experimental pilot study examining the effects of spiritual nursing care education based in biblical truth on pediatric nurses' competence in providing spiritual nursing care. Retrieved from http://digitalcommons.cedarville.edu/cgi/viewcontent.cgi?article=1008\&context=nursing_t hese

Martínez, B. B., \& Custódio, R. P. (2014). Relationship between mental health and spiritual wellbeing among hemodialysis patients: a correlation study. São Paulo Medical Journal= Revista Paulista De Medicina, 132(1), 23-27. doi:10.1590/1516-3180.2014.1321606

Meyer, C. (2003). How effectively are nurse educators preparing students to provide spiritual care?. Nurse Educator, 28(4), 185-190.

Mitchell, D., Bennett, M., \& Manfrin-Ledet, L. (2006). Spiritual development of nursing students: Developing competence to provide spiritual care to patients at the end of life. Journal of Nursing Education, 45(9), 365-370.

Musarezaie, A., Naji Esfahani, H., Momeni Ghaleghasemi, T., Karimian, J., \& Ebrahimi, A. (2012). The relationship between spiritual wellbeing and stress, anxiety, and depression in patients with breast cancer. (English). Journal of Isfahan Medical School, 30(195), 1-10.

Pearce, M., Coan, A., Herndon, J., Koenig, H., \& Abernethy, A. (2012). Unmet spiritual care 
needs impact emotional and spiritual well-being in advanced cancer patients. Supportive Care in Cancer, 20(10), 2269-2276. doi:10.1007/s00520-011-1335-1

Penman, J., Oliver, M., \& Harrington, A. (2013). The relational model of spiritual engagement depicted by palliative care clients and caregivers. International Journal of Nursing Practice, 19(1), 39-46. doi:10.1111/ijn.12035

Philips, P. L., \& Lazenby, M. (2013). The emotional and spiritual well-being of hospice patients in Botswana and sources of distress for their caregivers. Journal of Palliative Medicine, 16(11), 1438-1445. doi:10.1089/jpm.2013.0114

Pike, J. (2011). Spirituality in nursing: A systematic review of the literature from 200610. British Journal of Nursing, 20(12), 743-749.

Soper, D., (2014). Statistics calculators: Post-hoc statistical power calculator for a student t-Test. Retrieved from http://www.danielsoper.com/statcalc3/calc.aspx?id=49

Taylor, E. J. (2005). What have we learned from spiritual care research? Journal of Christian Nursing, 22(1), 22-28.

Tiesinga, L. J., Middel, B., Post, D., Jochemsen, H., \& Van Leeuwen, R. (2009). The validity and reliability of an instrument to assess nursing competencies in spiritual care. Journal of Clinical Nursing, 18(20), 2857-2869. doi:10.1111/j.1365-2702.2008.02594.x

Vallurupalli, M., Lauderdale, K., Balboni, M., Phelps, A., Block, S., Ng, A., \&Balboni, T. (2012). The role of spirituality and religious coping in the quality of life of patients with advanced cancer receiving palliative radiation therapy. Journal Of Supportive Oncology,10(2), 81-87. 
Van Leeuwen, R., Tiesinga, L., Middel, B., Post, D., \& Jochemsen, H. (2008). The effectiveness of an educational programme for nursing students on developing competence in the provision of spiritual care. Journal of Clinical Nursing, 17(20), 2768-2781. doi:10.1111/j.1365-2702.2008.02366.x

Van Leeuwen, R., Tiesinga, L., Middel, B., Post, D., \& Jochemsen, H. (2009). The validity and reliability of an instrument to assess nursing competencies in spiritual care. Journal of Clinical Nursing, 18(20), 2857-2869. doi:10.1111/j.1365-2702.2008.02594.x. 